\title{
DESENVOLVIMENTO REGIONAL - VIME DO CAMPO MAGRO
}

\author{
Irene H. Costas ${ }^{1}$, José A. Ribas ${ }^{2}$ \\ Marco A. H. Vasconcellos, Gleicilene N. dos Santos ${ }^{3}$
}

\section{RESUMO}

O municipio de Campo Magro, PR, tinha no vime uma atividade complementar a cultura vitivinicola. Desaparecendo a produção local os 1.200 artesão que o utilizavam passaram a importar matéria-prima e processá-la empregando substâncias prejudiciais ao meio ambiente. A cadeia produtiva desagregada, ainda favorecia a evasão de divisas do municipio situado em Área de Proteção Ambiental. Nesse contexto o trabalho visa desenvolver a sustentabilidade da cadeia produtiva do vime na regiāo, isto é, promover o cultivo do vime agregando todas as atividades da cadeia produtiva (plantio, manutenção, colheita, beneficiando, armazenagem, artesanato e comercialização); incentivando o cultivo em áreas marginais e utilizando māo de obra rural marginal; proporcionar a capacitação de artesāos e a inclusão de pessoas carentes e com necessidades especiais na atividade artesanal; evitando o consumo de fibras naturais extrativas e o uso de produtos quimicos tóxicos nocivos. Propiciando o desenvolvimento econômico-social sustentável dos habitantes da região e ainda ações para coibir a evasão de recursos financeiros do municipio, através da construção um arranjo produtivo local.

A primeira fase do trabalho envolveu produtores agricolas com áreas marginais de cultivo que poderão atender o mercado local de 1.200 artesãos utilizando 400 toneladas de vime seco, estimado em RS 1.200.000. O consumo de produtos acabados, em Curitiba, são 40 lojas do ramo de móveis, artigos para decoração e artesanato, consumindo aproximadamente RS 10.000.000. Os indicadores de viabilidade econômica, apresentaram valores positivos - TIR acima de 59,39\% e VPL superior a RS 29.556 - para as várias alternativas de investimento consideradas, isto é, plantio com recursos próprios, com recursos do PRONAF "C", "D" E "E", demonstrando assim a sustentabilidade do projeto.

Palavras-chave: Sistemas ecológicos e econômicos, cadeia produtiva do vime

1-NIPEA/FACINTER nipea@facinter.br

2-Gerente da Agência Campo Magro/BANCO DO BRASIL

3-TELEPAR 


\section{DESARROLLO REGIONAL - MIMBRE DE CAMPO MAGRO}

\section{RESUMEN}

El Municipio de Campo Magro tenia en el mimbre una actividad complementaria al cultivo vitivinicola. La producción local desapareció y los 1.200 artesanos que la utilizaban pasaron a importar matéria prima y la procesan empleando substancias perjudiciales para el medio ambiente. La cadena productiva desagregada todavia favorecia la evasión de divisas del municipio situado en Área de Protección Ambiental. Em este contexto el trabajo busca deasrrollar la sustentabilidad de de la cadena productiva de mimbre em la región, esto agregando todas las actividades de la cadena productiva (plantación, mantención, colecta, elaboración, almacenamiento y comercialización), incentivando El cultivo en áreas marginales y utilizando mano de obra rural marginal; proporcionando capacitación a los artesanos e incluyendo personas necesitadas a la actividad artesanal; y evitando el consumo de fibras sintéticas y productos químicos nocivos. De este modo se propicia el desarrollo econômico y social sustentable para los habitantes de la región y se suma acciones para cohibir la evasión de dineros del municipio, mediante um arreglo productivo local.

La primera fase del trabajo invólucro a productores agricolas em áreas marginales de cultivo que pudieran atender a 1.200 artesanos y utilizar 400 t de mimbre seco, estimado en R $\$$ 1.200.000. El consumo de productos acabados en Curitiba son 40 tiendas del ramo de muebles, artículos para decoración y artesanado por valor de unos $R \$ 10.000 .000$. Los indicadores de viabilidad econômica presentaron valores positivos, TIR sobre $59,4 \%$ y VPN superior a R $\$$ 29.556, para lãs varias alternativas de inversión consideradas, esto es plantación com recursos propios, com recursos de PRONAF "C", "D" e "E", demostrando asi la sustentabilidad del proyecto.

Palabras clave: Sistemas ecológicos y econômicos, cadena productiva de mimbre 


\section{INTRODUÇÃO}

O desenvolvimento sustentável deve estar incutido na triplice visāo do economicamente viável, socialmente justo e ambientalmente correto e conceituado de acordo com a Comissão Mundial de Meio Ambiente e Desenvolvimento das Naçōes Unidas (UNCED). Em seu “Relatório Brundland", chamado Nosso Futuro Comum (Our Common Future), "desenvolvimento sustentável é aquele que atende às necessidades do presente, sem comprometer a possibilidade de as gerações futuras atenderem a suas próprias necessidades".

O desenvolvimento regional sustentável é uma das grandes preocupaçōes globais da atualidade. Em regiōes onde a industrialização é precária, seja por falta de interesse de investidores, seja por sua localização ou acesso ou por estar localizada em áreas de proteção ambiental, essa preocupação se torna mais evidente. O diagnóstico das atividades desenvolvidas nessas regiōes é necessário para a busca do desenvolvimento regional, buscando-se agregar valor em toda a cadeia produtiva; incentiva-se a manutenção das pessoas no seu local de origem, aprimorando-se os processos produtivos, capacitando as pessoas e tornando os produtos e serviços competitivos no mercado consumidor, sem se descuidar da responsabilidade social e ambiental.

Campo Magro, colonizado por imigrantes italianos dedicados à agricultura, principalmente à viticultura, desde o inicio de sua colonização recebeu a implantação da cultura do vime. No inicio, o vime foi utilizado na confecção de cestos para a colheita da uva e de protetores de garrafōes de vinho; mais tarde, esse artesanato foi aprimorado para a confecção de outros objetos, como cestaria. artefatos de decoração e móveis. Mesmo com a expansāo do uso do vime pelos artesãos, as culturas de vime da região foram dizimadas e o seu cultivo comercial deixou de ser realizado, passando a ser adquirido de outras regiōes, principalmente do estado de Santa Catarina.

Atualmente, praticamente todo o vime consumido na região é adquirido de produtores do planalto lageano de Santa Catarina, estando os consumidores sujeitos ao custo de transporte. a preços estipulados pelos produtores ou pelos atravessadores que adquirem a produção no periodo de colheita para especular com o aviltamento de preços quando a mercadoria se torna escassa.

As condiçōes climáticas da regiāo sāo satisfatórias à produçāo do vime, reconhecendose a possibilidade de se produzir matéria prima para satisfazer toda a demanda local e substituir o consumo de fibras extrativas e fibras sintéticas pelo vime.

Apesar de ser a principal matéria-prima utilizada no pólo de artesanato de Campo Magro todo o vime consumido é adquirido no estado de Santa Catarina. Além do vime, os artesãos utilizam fibras sintèticas, geradoras de residuos prejudiciais ao meio ambiente, e o junco extraido das florestas do norte do Brasil, que, além de seu caráter extrativo, utiliza soda cáustica no seu beneficiamento, gerando residuos maléficos ao meio ambiente.

O pólo de vime de Campo Magro concentra aproximadamente 1.200 artesãos, distribuidos em pequenas fábricas de móveis artesanais de vime, com prestadores de serviço 
recebendo por tarefa, e a grande maioria desenvolvendo a sua arte de maneira informal. A informalidade da atividade leva esses atores a abrir mão de direitos sociais básicos, além de proporcionar grande evasão de renda do Municipio.

A cadeia de produção è desagregada, não havendo definição de uma linha de produção padronizada, voltada para a qualidade, a ergonomia ou o design das peças produzidas: esses fatores não permitem a identificação da produção local. A produção informal facilita a ação dos atravessadores no estabelecimento do preço do produto acabado; como não há sistema de associativismo, os artesãos estão sujeitos a essas injunçōes comerciais.

\section{OBJETIVOS}

Desenvolver a cadeia produtiva do vime segundo os principios de sustentabilidade, promovendo-se o cultivo do vime na região de Campo Magro, incentivando-se o uso de terras marginais nas áreas rurais; maximizando-se o uso da mão de obra nas propriedades rurais, agregando-se valor à produção através da capacitação dos produtores para a atividade artesanal. Incluir o artesanato em fibras naturais na grade curricular, da rede de ensino público municipal, na disciplina de educação artística; garantir a inclusão social de pessoas carentes e pessoas com necessidades especiais, através da capacitação artesanal. Preservar as áreas de proteção ambiental locais, através da recomposição de mata ciliar com o cultivo de vime e a extinção do uso de produtos químicos nocivos ao meio ambiente; preservar o meio ambiente externo através da redução do uso de fibras naturais extrativas e de fibras sintéticas nas atividades artesanais e coibir a evasão de receita e de recursos financeiros do municipio, através da construção um arranjo produtivo local.

\section{SITUAÇÃO ATUAL DO MUNICIPIO DE CAMPO MAGRO}

Campo Magro, cidade metropolitana da grande Curitiba, limitando com a Capital do Paraná e com os Municipios de Campo Largo, Almirante Tamandaré e Itaperuçu, com aproximadamente 25.000 habitantes, foi desmembrado do Municipio de Almirante Tamandaré em 1997. Colonizado por imigrantes italianos e poloneses tem sua economia baseada na agricultura, no turismo rural e na atividade informal de artesanato de móveis e cestaria em fibras naturais e artificiais.

\section{Área de Proteção Ambiental}

O municipio está localizado em área de proteção ambiental, contendo em sua área territorial o aqüifero do Rio Verde e o aqüifero do Passaúna. Esta condição de proteção ambiental limita a instalação de indústrias no municipio, interferindo diretamente nas atividades econômicas locais. Uma alternativa para essa deficiência econômica é a indústria do Turismo Rural que se encontra em franca expansão, criando uma fonte de geração de renda para os empreendedores a partir de suas propriedades originais, dispensando altos investimentos em estrutura e sofisticação. 
Acredita-se que, no futuro, o municipio de Campo Magro venha a se tornar uma regiāo de residências de alto padrāo, tendo em vista a sua proximidade da Capital, a qualidade de vida dos moradores e o seu perfil geográfico que oferece, além das belezas naturais, a opçảo de diversos esportes naturais e ecológicos.

Grande parte da arrecadação municipal vem do ICMS ecológico gerado por se tratar de área de mananciais.

\section{Atividades Econômicas: O Artesanato}

Verifica-se uma grande evasão de divisas geradas pela atividade informal de artesanato de móveis e cestaria. Estes são confeccionados em Campo Magro por seus artesãos e transportados para Curitiba e outras regiōes sem a geração dos tributos devidos. Destas áreas seguem para o mercado nacional como se fossem confeccionados nesses locais.

A atividade artesanal consome cerca de 400 toneladas de vime seco ao ano. Esta mesma quantidade é consumida em junco e fibras artificiais. Toda esta matéria prima é importada: o vime vem em sua totalidade do Planalto Lageano de Santa Catarina; o junco vem do Norte do Brasil e as fibras artificiais vêm da indústria nacional.

O beneficiamento do junco necessita do uso de soda cáustica no seu tratamento. Esse procedimento é realizado na propriedade dos artesãos e seus residuos são jogados na natureza, sem a devida reciclagem e nenhuma preocupaçāo com os danos causados ao meio ambiente.

Há uma desarticulação generalizada na atividade artesanal da região. A produção é desorganizada e os artesãos se obrigam a acatar o preço ditado pelos atravessadores que levam os produtos por preço vil, sem a geração de tributos para o Município. Isto faz com que a renda dos artesãos seja baixa e que haja, conseqüentemente, uma queda na qualidade do artesanato produzido.

Os artefatos de vime confeccionados em Campo Magro sāo conhecidos e aceitos em diversas regiōes do Pais, apesar de serem considerados produtos de Santa Felicidade (Curitiba-PR).

\section{O Cultivo do Vime}

O vime foi cultivado em Campo Magro durante muitos anos pelos colonizadores italianos que o utilizavam na atividade da viticultura, na confecção de cestos utilizados para a colheita da uva, confecçāo de cestos para proteção dos garrafōes de vidro e a utilizaçāo de galhos finos de vime para a amarração dos parreirais. Apesar do alto consumo de matéria-prima, as lavouras de vime da região foram abandonadas. Resta, atualmente, apenas uma pequena lavoura de vime produtiva, hoje com 37 anos de idade, sendo que toda a matéria utilizada vem de Santa Catarina. 
Estudos elaborados pela Epagri em Santa Catarina têm determinado a qualidade especifica necessária para cada tipo de utilização do vime. Estes estudos orientam o cultivo de variedades adaptadas para esses determinados usos, maximizando a produtividade das áreas cultivadas.

Atualmente o ciclo de produção do vime na região é uma atividade desarticulada, apesar de movimentar grandes valores monetários, deixando de produzir tributos necessários ao governo municipal, de agregar uma renda positiva para os artesãos e uma renda para produtores rurais locais.

\section{PROPOSTA DE DESENVOLVIMENTO DA CADEIA DE PRODUÇÃO DO VIME EM CAMPO MAGRO}

\section{Público Alvo}

Produtores agricolas com áreas marginais de cultivo, artesãos de fibras naturais, estudantes da rede pública de ensino, pessoas carentes, pessoas com necessidades especiais e internos da Fazenda Solidariedade (pessoas em tratamento de dependência quimica, pessoas com deficiência mental e idosos sem referencia familiar).

\section{Mercado}

O mercado potencial local è de 3.000 consumidores de matéria prima, utilizando 400 toneladas de vime seco, estimado em R\$ 1.200.000. Com o desenvolvimento do projeto de sustentabilidade, através da substituição de outras fibras pelo vime, esse mercado poderá duplicar em curto prazo. Após atingir $100 \%$ do consumo local de matéria prima, a produção poderá ser exportada para outros centros consumidores, onde o limite de potencial de mercado será definido pela concorrência com os produtores de Santa Catarina e com fibras importadas de outros paises.

Para consumo de produtos acabados, em Curitiba, aproximadamente 40 lojas do ramo de móveis, artigos para decoração e artesanato, consumindo aproximadamente $\mathrm{R} \$ 10.000 .000$. Considerando o mercado nacional, teriamos um consumo estimado em $R \$ 130.000 .000$ distribuidos nas Capitais e grandes centros comerciais.

\section{Posicionamento do Vime no Mercado de Campo Magro}

O vime produzido em Campo Magro, como matéria prima para os artesãos de fibras naturais, é uma novidade muito aguardada pelos consumidores; as perspectivas de vantagem competitiva quanto ao preço e à produção de variedades mais adequadas ao uso artesanal certificam o posicionamento do produto no mercado local.

Os artefatos de vime confeccionados em Campo Magro são conhecidos e aceitos em diversas regiões do País, apesar de serem considerados produtos de Santa Felicidade (CuritibaPR); o desenvolvimento da cadeia produtiva com a melhoria na qualidade dos produtos, além da certificaçāo de origem e respeito ambiental certamente conferem ao produto uma fixação 
mercadológica positiva.

\section{Marketing Táctico}

- Produto

O que se oferece ao mercado consumidor de matéria prima, é um produto de fibras naturais cultivadas em áreas marginais e utilização de mão de obra ociosa, evitando a utilização de material extrativo e fibras artificiais.

A produçāo local de matéria prima com criação de emprego e renda para produtores locais; a possibilidade de redução de custo de produção e a inexistência de custo de frete, já que a matéria prima será utilizada no local de transformação; a possibilidade de exportação do excedente da produção e a substituição da utilização de fibras extrativas e fibras sintéticas por fibras cultivadas, conferem ao produto a preferência do consumidor pela redução do custo e pelo benefício social agregado à produção.

- Preço

O preço do vime cultivado em Campo Magro é a grande vantagem competitiva do produto apresentado. A transformação do produto no próprio local de produção, evitando-se custo de transporte é responsável pela atratividade comercial. A estrutura de armazenagem do produto através do sistema associativista de logistica também será componente definitivo para a formação do preço do produto.

- Praça

Em Campo Magro estão concentrados cerca de 1200 artesãos; a princípio, a produção de matéria prima será destinada a esse público, através de venda cooperativa direta.

A produção de material acabado será realizada através de comercialização indireta, destinada a varejistas do ramo de móveis em fibras naturais, artesanato e objetos de decoração.

\section{- Promoção}

A promoção estará concentrada na disseminação de conhecimento e aprendizado, realizada através de seminários, palestras, encontros e treinamentos dos atores interessados. Os participantes dessas atividades serão multiplicadores das informaçōes adquiridas a respeito do projeto.

Junto ao público consumidor será disseminada a cultura de sustentabilidade da produção com ênfase na inclusão social gerada pelo projeto, na qualidade e procedência dos produtos e na responsabilidade ambiental. 


\section{- Projeção de Vendas}

Para a produção de matéria prima, estima-se o cultivo imediato de aproximadamente 100 ha, para atendimento da demanda local no prazo de três anos, ou seja, aproximadamente 1.200 toneladas de vime seco ao ano. Quando se atingir a totalidade do mercado local, o excedente de produção será direcionado para outros mercados consumidores potenciais, principalmente as regiões sudeste e nordeste, onde a produção poderá ser comercializada com vantagens competitivas quanto ao preço e a logistica de distribuição.

Para o produto acabado, a ênfase será em função do registro real de produção e comercialização, tendo em vista que na atualidade quase a totalidade da produção é registrada em Santa Felicidade. Este fato distorce as informaçōes de produção local e não permite registros estatísticos de produção e comercialização.

\section{- Investimento}

O investimento em marketing para o presente empreendimento compreende valores reduzidos, considerando-se que todo o marketing institucional estará concentrado em palestras, seminários e encontros que serão ministrados por instituições parceiras, que por interesse ou constituição estatutária participarão voluntariamente do projeto.

\section{- Análise de Equilíbrio}

A análise de equilibrio nos remete ao sucesso do empreendimento considerando-se a manutenção da atividade artesanal, mesmo com a importaçāo integral de matéria prima.

\section{Pontos Fortes:}

Produção de matéria prima no próprio local de transformação.

Inserção de nova atividade em pequenas áreas rurais com o aproveitamento de áreas marginais e mão de obra ociosa.

Inclusão social, através da geração de rendas, para pessoas carentes, portadores de necessidades especiais, idosos e deficientes mentais.

Defesa e proteção do meio ambiente

Geração de divisas para o Município

Pontos fracos:

Desorganização da cadeia produtiva

Falta de padronização da produção de produtos acabados 
Utilização de produto químico nocivo ao meio ambiente na utilização de Junco como matéria prima.

- Oportunidades

A crescente demanda de mercado por produtos com garantia de procedência, garantia de qualidade, garantia de responsabilidade social e de produto ecologicamente correto gera a expectativa de consumo dos produtos artesanais com a marca Campo Magro.

- Controle sobre o Investimento

O controle sobre os investimentos será realizado através de pesquisa de satisfação de clientes e pesquisas estatisticas de produção e comercialização, com o objetivo de acompanhar a evolução e alcance dos objetivos colimados.

\section{ANÁLISE ECONÔMICO - FINANCEIRA}

Após o levantamento de todos os custos de produção, receita operacional e demais despesas para a implantação do projeto, realizá-se a análise econômica - financeira do empreendimento conforme os seguintes itens:

\section{Fluxo de caixa}

Com o cálculo do fluxo de caixa, com utilização de recursos próprios, conforme demonstração da Tabelas em Anexo, no primeiro ano haverá um déficit de $\mathrm{R} \$ 11.961$, sendo projetado para os próximos 6 anos e chegando a uma disponibilidade liquida de $R \$ 59.759$ no último periodo. As Tabelas em Anexo demonstram os valores utilizando-se recursos financiados através das linhas de crédito disponibilizadas para o empreendimento.

\section{Determinação de uma Taxa Minima de Atratividade}

A taxa minima de atratividade (TMA) demonstra o custo de oportunidade de capital para a o empreendimento, mostrando qual seria o ganho relativo se o capital não fosse investido no empreendimento, ou seja, è a taxa de juros que deixa de ser obtida na melhor aplicação do capital próprio. Considerou-se como base o indice do CDB para pessoas físicas, divulgado pelo Banco Central do Brasil - BACEN, no ano de 2004, que ficou em $13,87 \%$ ao ano.

\section{Taxa Interna de Retorno}

Foi apurada uma taxa interna de retorno - TIR, para a implantação do empreendimento com utilização de recursos próprios, de $59,39 \%$, quando se utilizou recursos do PRONAF "C", obteve-se uma TIR de 153,20\%, com recursos do PRONAF "D", uma TIR de 152,89\% e utilizando-se recursos do PRONAF "E", uma TIR de 145,45\%. 


\section{Tempo de Recuperação do Capital (Payback)}

Para a implantação do empreendimento com utilização de recursos próprios chegou-se ao resultado de 3 anos e 5 meses e com recursos financiados através das linhas de crédito do PRONAF "C", "D", os resultados foram 2 anos e 8 meses, 2 anos e 11 meses para a utilização de recursos financiados através do PRONAF " $E$ ".

O payback determina o periodo de tempo necessário para que a empresa recupere o valor inicialmente investido. Este método é amplamente utilizado pelas pequenas empresas, devido a sua facilidade de cálculo e ao apelo intuitivo. Sua regra básica é a seguinte: quanto mais tempo a empresa precisar esperar para recuperar o investimento, maior a possibilidade de perda; em contrapartida, quanto menor for o periodo de payback, menor será a exposição da empresa aos riscos.

A principal desvantagem é a de não considerar o valor do dinheiro no tempo, ou seja, não descontar os valores futuros do fluxo de caixa, sendo simplesmente um periodo de tempo máximo aceitável, determinado subjetivamente, através das entradas de caixa no momento em que ocorrem, e o fluxo alcançando seu ponto de equilibrio (as entradas se igualam ao investimento). Outra desvantagem é a de que o payback não reconhece os fluxos de caixa que ocorrem após o periodo de recuperação do capital, portanto, ignorando todo o retorno projetado para o projeto.

Em termos práticos, o payback é o momento em que o saldo acumulado do fluxo de caixa se iguala ao valor do investimento inicial.

\section{CONCLUSÃO}

A localização do municipio, em área de preservação ambiental, com aqüiferos em seu subsolo, oferece áreas marginais que não podem ser aproveitadas com outras culturas. Os produtores têm baixo retorno financeiro de suas terras exatamente por não poderem fazer muitas alterações em seus solos.

A preservação ambiental decorrente do cultivo do vime torna-se evidenciada quando consideramos um comparativo com outras matérias-primas, como o junco. Além do fato de não necessitar do manuseio de produtos químicos agressores do meio ambiente em seu beneficiamento, evita que fibras extrativas, sem possibilidades de replantio, sejam colhidas, 0 que prejudica, por sua vez, florestas nativas.

O momento político do municipio indica melhorias de infra-estrutura, seja de origem municipal ou estadual. A perspectiva de melhoria em sua rede viária, de ligação à Capital Curitiba, deixa antever um maior desenvolvimento à região. Com isso, a produção de artesanato local, bem como a exportação da produção de matéria-prima oriunda do municipio, são ainda mais promissoras.

$\mathrm{Na}$ situação presente, o municipio perde em arrecadação, pois quase toda sua produçāo de artefatos de vime é exportada para outras cidades, de maneira informal. $\mathrm{O}$ 
mercado desconhece a produção de Campo Magro porque é apresentada em outros locais sem identificação de procedência.

Considerando-se as informações acima expostas, podemos concluir que um projeto de sustentabilidade regional, ambientalmente exemplar, de implantaçảo de uma cadeia de produção de vime em Campo Magro torna-se mais que viável. Vantagens econômicas, fiscais, sociais e ambientais garantem esta viabilidade. Produzir em àreas marginais não utilizadas; possibilitar um melhor retorno financeiro a produtores com baixo aproveitamento em suas terras: trazer maior arrecadação fiscal ao municipio, indicando claras possibilidades de um maior desenvolvimento; possibilitar trabalho à mão-de-obra não aproveitada; organização dos produtores artesanais locais; além do fato do vime ser ambientalmente correto; todos estes fatores, somados ao fato do desenvolvimento social como um todo que este projeto pode trazer.

Os indicadores de viabilidade econômica apresentaram valores positivos -TIR acima de $59 \%$ e VPL superior a R\$29.556 - para as várias alternativas de investimento consideradas, isto é, plantio com recursos próprios, com recursos do PRONAF "C", "D" e "E", demonstrando assim a sustentabilidade do projeto.

\section{REFERÊNCIAS}

Abreu, Paulo F. S P; Stephan, Christian, 1982. Análise de investimentos. $1^{\text {a }}$ edição. Rio de Janeiro: Editora Campus.

Banco Central do Brasil. http://www.bacen.gov.br

Banco do Brasil SA. http://www.bb.com.br

Capra, Fritjof, 2002. As conexões ocultas - Ciência para uma vida sustentável. $3^{a}$ edição. São Paulo: Editora Pensamento.

Casaroto Filho, Nelson; Pires, Luis Henrique, 2001. Redes de pequenas e médias empresas e desenvolvimento local. $2^{a}$ ediçāo. São Paulo: Editora Atlas.

Paladini, Edson Pacheco, 2004. Gestão da qualidade. $2^{a}$ edição. São Paulo: Editora Atlas.

Sanvicente, Antonio Zoratto, 1997. Administração financeira. $3^{\text {a }}$ edição. São Paulo: Editora Atlas.

Valeriano, Dalton L, 2001. Gerenciamento estratégico e administraçāo por projetos. $1^{\mathrm{a}}$ ediçāo. São Paulo: Makron Books. 


\section{ANEXO}

FLUXO DE CAIXA SEM CONSIDERAR FINANCIAMENTOS (EM R\$)

\begin{tabular}{|l|c|c|c|c|c|c|c|}
\hline ANO & $\mathbf{1}$ & $\mathbf{2}$ & $\mathbf{3}$ & $\mathbf{4}$ & $\mathbf{5}$ & $\mathbf{6}$ & $\mathbf{7}$ \\
\hline INVESTIMENTOS (-) & $11.961,00$ & & & & & & \\
\hline ENTRADAS (+) & & $5.940,00$ & $11.880,00$ & $18.000,00$ & 23.940 .00 & 27.000 .00 & $28.488,00$ \\
\hline SAIDAS (-) & & $3.714,56$ & $5.319,40$ & $6.921,00$ & $8.490,20$ & 9.541 .00 & $9.541,00$ \\
\hline SALDO & $(11.961,00)$ & $2.225,44$ & 6.560 .60 & $11.079,00$ & $15.449,80$ & $17.459,00$ & $18.947,00$ \\
\hline $\begin{array}{l}\text { SALDO OPERACIONAL } \\
\text { FINAL }\end{array}$ & $(11.961,00)$ & $(9.735,56)$ & $(3.174,96)$ & $7.904,04$ & $23.353,84$ & $40.812,84$ & $59.759,84$ \\
\hline TIR $=$ & $59,39 \%$ & VPL $=$ & RS 29.556.92 & & PAYBACK $=$ & \multicolumn{3}{|c|}{ 3 Anos e 5 Meses } \\
\hline FLLXO & & & &
\end{tabular}

FLUXO DE CAIXA CONSIDERANDO PRONAF 'C' (EM R\$)

\begin{tabular}{|l|c|c|c|c|c|c|c|}
\hline ANO & $\mathbf{1}$ & $\mathbf{2}$ & $\mathbf{3}$ & $\mathbf{4}$ & $\mathbf{5}$ & $\mathbf{6}$ & $\mathbf{7}$ \\
\hline INVESTIMENTOS $(-)$ & $11.961,00$ & & & & & & \\
\hline ENTRADAS $(+)$ & $10.176,00$ & 5.940 .00 & $11.880,00$ & 18.000 .00 & $23.940,00$ & $27.000,00$ & $28.488,00$ \\
\hline SAIDAS $(-)$ & & $5.874,31$ & $7.543,95$ & $9.214,18$ & $10.852,17$ & $11.273,83$ & $9.541,00$ \\
\hline SALDO & $(1.785,00)$ & 65.69 & 4.336 .05 & $8.785,82$ & $13.087,83$ & $15.726,17$ & $18.947,00$ \\
\hline $\begin{array}{l}\text { SALDO OPERACIONAL } \\
\text { FINAL }\end{array}$ & $(1.785,00)$ & $(1.719,31)$ & $2.616,74$ & $11.402,56$ & 24.490 .39 & $40.216,56$ & $59.163,56$ \\
\hline TIR = & $153,20 \%$ & VPL $=$ & R\$ 32 257.47 & & PAYBACK = & 2 Anos e 8 Meses \\
\hline
\end{tabular}

\section{FLUXO DE CAIXA CONSIDERANDO PRONAF 'D' (EM R\$)}

\begin{tabular}{|l|c|c|c|c|c|c|c|}
\hline ANO & $\mathbf{1}$ & $\mathbf{2}$ & $\mathbf{3}$ & $\mathbf{4}$ & $\mathbf{5}$ & $\mathbf{6}$ & $\mathbf{7}$ \\
\hline INVESTIMENTOS (-) & 11.961 .00 & & & & & & \\
\hline ENTRADAS $(+)$ & 10.176 .00 & $5.940,00$ & 11.880 .00 & $18.000,00$ & $23.940,00$ & $27.000,00$ & $28.488,00$ \\
\hline SAIDAS (-) & & 5.874 .31 & $7.543,95$ & $9.214,18$ & $10.852,17$ & $11.973,83$ & 9.541 .00 \\
\hline SALDO & $(1.785,00)$ & 65.69 & $4.336,05$ & $8.785,82$ & $13.087,83$ & $15.026,17$ & $18.947,00$ \\
\hline & & & & & & & \\
\hline $\begin{array}{l}\text { SALDO OPERACIONAL } \\
\text { FINAL }\end{array}$ & $(1.785,00)$ & $(1.719,31)$ & $2.616,74$ & $11.402,56$ & $24.490,39$ & 39.516 .56 & $58.463,56$ \\
\hline TIR = & $152,89 \%$ & VPL $=$ & RS 31.891,83 & & PAYBACK $=$ & 2 Anos e 8 Meses \\
\hline
\end{tabular}

FLUXO DE CAIXA CONSIDERANDO PRONAF 'E' (EM R\$)

\begin{tabular}{|c|c|c|c|c|c|c|c|}
\hline ANO & 1 & 2 & 3 & 4 & 5 & 6 & 7 \\
\hline INVESTIMENTOS (-) & $11.961,00$ & & & & & & \\
\hline ENTRADAS (+) & $10.176,00$ & $5.940,00$ & 11.880 .00 & 18.000 .00 & 23.940 .00 & 27.000 .00 & 28488 \\
\hline SAIDAS (-) & & 6.055 .56 & $7.830,12$ & 9.625 .24 & 11.390 .50 & 12.651 .57 & 9.541 .00 \\
\hline SALDO & $(1.785,00)$ & $(115,56)$ & 4.049 .88 & $8.374,76$ & $12.549,50$ & $14.348,43$ & $18.947,00$ \\
\hline $\begin{array}{l}\text { SALDO OPERACIONAL } \\
\text { FINAL }\end{array}$ & $(1.785,00)$ & $(1.900 .56)$ & $2.149,32$ & 10.524 .08 & 23.073 .58 & 37.422 .01 & 56.369 .01 \\
\hline $\mathrm{TIR}=$ & $145,45 \%$ & $\mathrm{VPL}=$ & $\begin{array}{c}\text { RS } \\
30.559,35\end{array}$ & & $\begin{array}{c}\text { PAYBACK } \\
=\end{array}$ & 2 Anos $\mathrm{e}$ & 1 Meses \\
\hline
\end{tabular}

